DOI: $10.30972 /$ eitt.704766

\title{
La valorización como medio de concientización del cuidado del ambiente
}

\section{Sogari Elena I. ${ }^{1}$; Sogari Noemí ${ }^{2}$}

\section{Resumen}

La educación ambiental a lo largo de las vida humana es una estrategias necesaria, para incentivar y propiciar el cuidado ambiental, motivando la participación y compromiso de la sociedad correntina.

Este artículo presenta los resultados obtenidos en el marco de un proyecto de Extensión aprobado y subsidiado por la Facultad de Derecho de la UNNE, cuyo objetivo fue difundir el conocimiento científico en el ámbito de la educación referente al cuidado del ambiente.

Se trabajó en este proyecto con algunas disciplinas curriculares del último año lectivo del establecimiento C.E.S.P.A N 5, es un colegio nocturno para adultos. Cuyo eje central fue el ambiente, con el objeto de concientizar y valorar los recursos naturales de nuestra provincia, señalando la necesidad del compromiso como consumidores responsables para favorecer un uso sostenible, aportando soluciones a los problemas locales, mediante la necesidad de cambios de conductas con el ambiente.

\footnotetext{
${ }^{1}$ Facultad de Derecho y Ciencias Sociales y Politicas. UNNE. Integrante de GIESMA - Investigadora de la Facultad de Derecho y Ciencias Sociales y Políticas. UNNE. elena_sogari@yahoo.com.ar y mariaelenasogari@gmail.com.

${ }^{2}$ Facultad de Ciencias Exactas y Naturales y Agrimensura. UNNE. Directora del GIESMA FaCENA. Directora de los Proyectos PI 17F015 Producción de bioenergía, producción de agua de reusó y reciclado de nutrientes a partir de efluentes. Pl16Foog Estudio y caracterización de calefones solares construidos por alumnos de la FaCENA para su instalación en zonas rurales. SGCYT- UNNE. noemisogari@gmail.com.
} 
Induciendo a la cooperación y colaboración para mayor desarrollo y articulación entre el cuidado al ambiente y las conductas humanas al momento de utilizar los recursos naturales para la producción y consumo.

\section{Introducción:}

El escenario apropiado para inculcar el cuidado al ambiente es la educación, para que nuestra sociedad, aprenda colectivamente a convivir, producir y consumir, acorde con la equidad y racionalización en el uso común (Pastorino L. , 2005).

Referente al uso de nuestros recursos naturales, es abundante en nuestra zona, al punto de no tomar las medidas preventivas, ante la explotación demográfica, el incremento de urbanización, de marginalidad social y consumo de bienes materiales y culturales. Estas situaciones fácticas van concatenadas con el avance acelerada de la producción de residuos sólidos, líquidos y gaseosos que se van depositando en la provincia de Corrientes.

El deterioro de los recursos naturales, provocado por los seres humanos, obliga a trabajar con este problema socio-ambiental y jurídico, en la que resulta difícil prever y decidir acerca de riesgos inmediatos, dada la incertidumbre existente y su evolución, como parte del resultado del cambio climático.

En la Cumbre de Río se adoptaron tres instrumentos de carácter no obligatorio relacionado con el cambio climático: A) declaración de Río sobre el Medio Ambiente y el Desarrollo, que comprenden las directivas generales. B) La Agenda 21, con las propuestas de acción, C) la Declaración sobre los bosques. Asimismo adoptaron dos convenciones de las partes ${ }^{3}$.

\footnotetext{
${ }^{3}$ Con ellos comenzó una etapa de mayor influencia del llamado soft law en los derechos internos y el derecho internacional en materia ambiental pasó a tener un rol mucho más efectivo ante el temor de algunos juristas (Remond- Gouilloud, Martine, Du droit de detruire, cit., Paris). De que el derecho sin fuerza obligatoria pudiese poner en riesgo su credibilidad. Sin embargo los trabajos de las diferentes conferencias, que marcan una serie de avances paulatinos y propuestas alentadoras para canalizar los objetivos generales fijados, si bien pueden no corresponderse con la velocidad deseada, son en general positivos. A partir del convenio de Cambio Climático y del protocolo de Kioto, alcanza una dimensión inusitada y genera propuestas y rumbos de acción válidos para un nuevo modelo a escala mundial (ver los artículos publicados en LL Suplemento Ambiental, 08/03/2001).
} 
La educación referente al ambiente, es un paso fundamental, para obtener cambios profundos en el imaginario colectivo. Esto implica que no resulta suficiente tomar los recaudos para utilizar tecnologías no convencionales, y de bajo costo sino que estos deben ir acompañados de toma de conciencia y valoración del uso de nuestros recursos naturales (Pastorino, 2005). Cabe resaltar que este trabajo, no fue considerado en el sentido figurado, que corresponde al discurso político o como fórmula programática de nuestra Constitución Nacional del año 1994, que fue incorporaron a nuestra Carta Magna los nuevos derechos, referente a la tercera generación y entre ellos los derechos de índole ambiental. Este trabajo fue considerado en el sentido técnico que a reemplaza la titularidad preexistente de los bienes individuales que conforman el "todo" ambiental (Pastorino L. , 2005), calificando al ambiente como un bien jurídico y a la vez señalando que los factores sociales, también forma parte del ambiente, ya que en ella también existe el hombre

Nuestra Constitución Nacional reconoce el disfrute de condiciones de vida adecuadas en un medio de calidad tal que le permita realizar una vida digna; es decir, que la persona humana debe proteger y mejorar el medio para las generaciones presentes y futuras.

Es necesario sostener que ese cambio de modelo resulte una condición relevante, para todos los ámbitos donde nuestros ciudadanos viven o tengas sus actividades cotidiana, es decir en el área urbano, rural (agrícola y ganaderos, pesquero, etc.).

A través de este proyecto se propuso contribuir con la educación ambiental y social, promoviendo la concientización y valoración al momento de utilizarlo, para la conservación de este recurso natural. Siendo indispensable acotar que para comprender a la ciencia jurídica ambiental debemos observar a la naturaleza, que es fuente para el desarrollo que se presenta en la humanidad.

Para el derecho clásico, pensar un bien fuera de esta óptica 4 ha sido irrelevante. La construcción de la doctrina, jurisprudencia o la misma ley al tratar el derecho

\footnotetext{
4 El autor Pastorino, menciona en su obra a D’Addino Serravale, recordando la tradición exposición de Pugliatti, la teoria del bien a la que normalmente el jurista hace referencia a un sistema de derechos subjetivos que encuentra su lógica en el objeto, identificando como quid externo al sujeto, punto referencial de un interés suyo, juridicamente protegido.
} 
ambiental considerado como un bien colectivo, de ese modo permitió superar las ideas clásicas, al punto de que hoy día posee protección jurídica.

Por lo que resulta más acertada utilizar en el campo del derecho, el siguiente concepto restringido y amplio. En el primero relacionando los recursos naturales como susceptible de apropiación y la segunda como susceptible de tutela (Lamberti, 1998). Que guarda relación con el derecho penal para identificar "un valor o interés” tomado en consideración por la norma represiva, asumido, por lo tanto, como objeto de protección (Pastorino L. , 2005).

Se trabajó con los alumnos correntinos, inculcando el cambio de conducta acordes con el modo de contribuir con el mundo desde nuestra provincia, resaltando que la educación ambiental, sea vista no como una reserva de consumo, sino como un ámbito de vida con valor en sí mismo.

Comprender y valorar nuestro entorno, implica a la vez que valorar de modo intrínseco nuestra salud y al ambiente.

La tutela objetiva nos permite identificar los valores de la sociedad. Estos valores son equiparados con la propia esencia de la vida. Aclarando que el valor no es considerado en el término exclusivamente económico sino, fundamentalmente existencial.

La educación no concluye con la finalización de los estudios, primarios, secundarios, terciarios o universitarios, adquiriendo determinados conocimientos científicos, para incorporarse al ámbito del trabajo. La finalidad del proyecto fue trabajado con los alumnos desarrollando la capacitación, la responsabilidad con ese grupo pequeño que pertenece a un sector de la comunidad educativa. Para tratar de incorporar los modelos de innovación y transformarlos en propuestas operativas.

\section{Metodología y Selección de Actividades:}

El grupo de trabajo estuvo integrado por docentes, investigadores y alumnos de la carrera de abogacía como también la carrera de la FACENA, cabe aclarar que el grupo de investigación es GIESMA (Grupo de Investigación, Desarrollo y Transferencia Tecnológica de Energías Sustentables y Cuidado del Medio Ambiente). 
El trabajo se desarrolló en el ámbito de la educación formal con transferencia virtual en las siguientes Comunidad Educativa específicamente en el C.E.S.P.A N 5 correspondiente a la provincia de Corrientes.

La entrega de las actividades se realizó desde la perspectiva inter-disciplinaria, señalando la causa: de las conductas humanas y sus consecuencias ambientes por no valorarlo. Las actividades consistieron en abordar la educación ambiental, con los alumnos del último año, considerando que "el ambiente" tiene un carácter integrador y globalizador, permitiendo desarrollarlo, en las dimensiones social-ambientales, que al ser trans-disciplinarias, fueron aplicados desde varias disciplinas en forma conjunta: desde la mirada científica (biología, física, sociológica, matemática, ect), cultural (ideología, valores, conductas, actitudes) e integradoras (aprendizaje, recreación). Reflejando aspectos sociales, políticos, jurídico y culturales y económico.

En matemática: la realización de encuestas, análisis de la información y elaboración de estadísticas son utilizadas en todos los trabajaos, para visualizar a simple vistas las conclusiones por medios de gráficos.

En física y química: La propuestas de acciones que colaboren con la preservación y cuidado del ambiente de modo cotidiano, como ser el aprovechamiento de energías no convencionales

En derecho, analizar documentos de debate a nivel mundial y legislativo existente. Analizando la dinámica de la participación ciudadana en materia del ambiente.

En geografía, el incremento demográfico, en Corrientes, nos lleva en la necesidad de proponer acciones concretas que colaboren con la preservación del acuífero guaraní- Ibera.

En tecnología: El uso e información de herramientas no agresivas con el medio ambiente fundamental para la conservación de nuestros recursos naturales.

En lengua: producción de textos escritos. 
En la sociología: analizar si las comunidades educativas, vecinales, religiosas abordan el tema del cuidado del ambiente.

Esto demuestra que el ambiente se encuentra vinculadas con las diferentes disciplinas mencionadas y otras disciplinas que no fueron mencionadas pero que guarda relación.

Este proyecto ejecutado, fue positivo porque desde nuestro conocimiento científico llevamos a los alumnos del establecimiento C.E.S.P.A N 5 a través del proyecto de extensión al medio, no solo la problemática socio-ambiental y jurídica señalando sus efectos sino además la necesidad de adquirir la militancia por el cambio, a fin de vivir con otras pautas de producción y consumo menos agresivas con el ambiente.

\section{Resultados}

La educación, posee un papel importante en nuestra comunidad correntina, fue por eso que el trabajo fue ejecutó en el marco educativo ambiental, con los alumnos del último año, del C.E.S.P.A $\mathrm{N}^{0} 5$.

Fue un aprendizaje significativo, al lograr que los alumnos comprendan, conceptos, procedimientos, actitudes y valores, con el fin inmediato, que los incorpore a su vida cotidiana y lo difunda. Desde la dimensión de los valores, la ética ambiental rige el principio de solidaridad al reconocer que el planeta es el espacio geográfico donde viven todos los seres humanos y por esa razón debería compartir y disfrutar de los bienes colectivos, conforme el manejo sustentable que nos ofrece los recursos naturales.

Como cierre de esta actividad, se le entregó a la rectora del establecimiento un cuadernillo con las actividades realizadas por los alumnos de dicho establecimiento para ser utilizado el año que viene en el ciclo lectivo.

Generando en los alumnos una conciencia ambiental y ciudadana, que se encuentra relacionada con el derecho-deber que constitucionalmente se garantiza al ciudadano a lo largo de su vida en relación, involucrando la relación de las personas humanas con su entorno ambiental. 


\section{Conclusiones}

Se considera que esta actividad fue muy positiva para la comunidad educativa, cuyo actores no fueron otros que ciudadanos correntinos, quienes trabajaron en el proyecto ejecutado, enlazado con la necesidad de seguir educando, formando y capacitando ambientalmente referente al valor y la necesidad ineludible de la cooperación y colaboración en el bien colectivo.

Rediseñar nuestras formas de vida es un compromiso que tenemos todos con el ambiente. El compromiso de los políticos también es necesario que como ideal debería ir de la mano con la conciencia colectiva para lograr la transición del cambio de conductas tanto en la producción como en el consumo de los recursos naturales valorando más el ambiente.

Es verdad que el estado Nacional tiene la obligación de colaborar para preservar y proteger al ambiente, conforme al principio de subsidiariedad y si fuera necesario participar en forma complementaria en el accionar de los ciudadanos. Referente a su funcionamiento, la subsidiariedad posee dos aspectos, uno positivo y el otro negativo. El primero implica que el Estado Nacional tiene la obligación de colaborar en tanto que la intervención de la Autoridad Nacional debe ejercerse sólo cuando sea necesario. El aspecto negativo, que la Autoridad Nacional debe abstenerse de asumir funciones que pueden ser cumplidas eficientemente por los ciudadanos. Resaltando que la intervención del Estado solo es concurrente y residual.

No resulta suficiente implementar más normas vinculado con el cuidado ambiental por parte del Estado Nacional, ni impulsar cambios tecnológicos no convencionales, o de analizar desde el punto económico las variables ambientales, si no se producen cambio sólido y profundo en la conciencia de nuestros ciudadanos, en el cuidado del ambiente. Es necesario seguir trabajando con la educación ambiental, que cumple una función orientar los procesos en este sentido, tanto cuando se trata de procesos formales como informales, en la escuela, en la familia, en la universidades, etc. 


\section{Bibliografía:}

Diaz Barriga, F. (2006) enseñanza situada. Mc Graw- Hill.

Lamberti, M. (1998). Derecho ambiental.

Pastorino, L. (2005). El Daño Al Ambiente. Buenos Aires: LexisNexis.

Pastorino, L. (2005). El Derecho Al Ambiente. LexisNexis. 